\title{
Electrical and photovoltaic properties of CuTPP/p-Si organic- inorganic hybrid hetrojunction
}

\author{
M.M.El-Nahass ${ }^{\mathrm{a}}$, Mossad EL- Metwally ${ }^{\mathrm{b}}$, A.A.M.Farag ${ }^{\mathrm{a}}$, Shokry Menshawy ${ }^{\mathrm{b}}$, \\ F.S.H. Abu-Samaha ${ }^{\mathrm{c}}$, Eman Elesh ${ }^{\mathrm{b}}$ \\ ${ }^{a}$ Thin Film Laboratory, Department of Physics, Faculty of Education, Ain Shams University, Roxy, 11757 \\ Cairo, Egypt \\ ${ }^{b}$ Department of Physics, Faculty of @Science, Port Said University, Port-Said, Egypt \\ ${ }^{c}$ Department of Physics \& Mathematical Engineering, Faculty of Engineering, Port-Said University, 42523
}

Port-Said, Egypt

\begin{abstract}
Thin films of 5,10,15,20-Tetraphenyl-21H,23H-porphine copper(II), CuTPP were prepared by conventional thermal evaporation technique on $p$-Si substrates to form CuTPP/p-Si organic-inorganic hybrid hetrojunction. The temperature-dependence of the electrical characteristics of the CuTPP/p-Si heterojunction in the temperature range of 298-353 K was studied. The barrier height and ideality factor of the heterojunction were determined as a function of temperature. It is noticed that the bias barrier height $\Phi_{b}$ increases and the ideality factor $m$ decreases by increasing the temperature. Such behavior can be attributed to barrier inhomogeneities by assuming a high mismatch in CuTPP /p-Si interface. The value of series $\left(R_{s}\right)$ and shunt $\left(R_{s h}\right)$ resistances were determined using junction resistance and found to be a strongly temperature. Variation of $1 / C^{2}$ with voltage shows a straight line at high frequency $(1 \mathrm{MHz})$ indicating the formation of barrier between CuTPP and p-Si and the potential barrier height is about $0.92 \mathrm{eV}$ at $298 \mathrm{~K}$. The photovoltaic properties of CuTPP /p-Si heterojunction were investigated under illumination and the main important parameters such as open circuit voltage, $V_{o c}$, and short circuit current, $I_{s c}$, were found to be $0.289 \mathrm{~V}$ and $0.03 \mathrm{~A}$, respectively.

Keywords: CuTPP thin film ; Heterojunction; Photovoltaic
\end{abstract}

\section{Introduction}

Organic solar cells promise to open up new markets for solar energy, potentially powering everything from watches and calculators to laptop computers. Their flexibility and minimal weight will allow them to be placed on almost anything from tents that would provide power to those inside, to clothing that would power personal electronic devices. [1-3] Because of the growing demand for renewable energy sources, the manufacturing of solar cells and photovoltaic arrays has advanced considerably in recent years[4].

Hybrid solar cells combine advantages of both organic and inorganic semiconductors. Hybrid photovoltaics have organic materials that consist of conjugated polymers that absorb light as the donor and transport holes and inorganic materials in hybrid cells are used as the acceptor and electron transporter in the structure [5].

In the late 1960s it was discovered that illuminated organic dyes can generate electricity at oxide electrodes in electrochemical cells [6]. As early as 1993, natural porphyrins and chlorophylls were being studied in dye-sensitized solar cell (DSSC) [7-8] and interest in these dyes has continued to grow. Porphyrins are perfectly suited for their integration in light energy conversion systems. These colored macrocycles exhibit very attractive physical properties, particularly very high extinction coefficients in the visible and near IR regions, where the maximum of the solar photon flux occurs, that is necessary for efficient photon harvesting [9]. Porphyrinoid derivatives and their DSSC performances has been the subject of several reviews in the last few years covering most cyclic tetrapyrrole derivatives [10-11].

In the present work the potential availability of the heterojunction based on CuTPP for photovoltaic application is presented. This work deals with the designing and characterization of the new type of heterojunction having configuration $\mathrm{Au} / \mathrm{CuTPP} / \mathrm{p}-\mathrm{Si} / \mathrm{Al}$. The electronic parameters controlling the heterojunction performance, such as barrier height, ideality factor, series resistance and interface parameters were evaluated by current-voltage and capacitance-voltage measurements. Moreover, the photovoltaic properties have been investigated by $\mathrm{I}-\mathrm{V}$ characteristics under illumination.

\section{Experimental Details}

$\mathrm{Au} / \mathrm{CuTTP} / \mathrm{p}-\mathrm{Si} / \mathrm{Al}$ heterojunction was prepared by using a polished and etching p-type single crystal silicon wafer with a thickness of $400 \mu \mathrm{m}$. The wafer was rinsed successively in distilled water for some time to remove any dust particles, followed by ethyl alcohol to remove any grease material and then washed in distilled 
water. The silicon wafer was etched using $\mathrm{CP}_{4}$ etching solution for $1.5 \mathrm{~min}$. Etching solution was prepared by adding $18 \mathrm{ml}$ of $\mathrm{HF}$ acid to $1.5 \mathrm{ml}$ of acetic acid and $57 \mathrm{ml} \mathrm{Conc}$. $\mathrm{HNO}_{3}$. After etching, the silicon wafer was washed for two minutes by distilled water and then by ethyl alcohol. After which the silicon wafer was coated from one side by aluminum electrode using thermal evaporation technique to fabricate the ohmic contact. The coating unit is supplied with a quartz crystal monitor (FTM4, Edwards) to determine the rate of deposition. The other side of silicon wafer was coated by CuTTP thin film with thickness $700 \mathrm{~nm}$ and the other masked electrode Au was deposited onto CuTPP thin film as ohmic contact.

The dark current-voltage (I-V) characteristics of $\mathrm{Au} / \mathrm{CuTTP} / \mathrm{p}-\mathrm{Si} / \mathrm{Al} \mathrm{p}-\mathrm{Si}$ heterojunction at different ambient temperatures, ranged from 293 to $353 \mathrm{~K}$, were measured by using a high impedance Keithley electrometers model 617. The capacitance-voltage $(\mathrm{C}-\mathrm{V})$ characteristics of fabricated $\mathrm{Au} / \mathrm{CuTPP} / \mathrm{p}-\mathrm{Si} / \mathrm{Al} \mathrm{p}-\mathrm{Si}$ heterojunction were measured at room temperature at $1 \mathrm{MHz}$ by using a computerized capacitance-voltage system, consisting of C-V meter (Model 4108) in air and at dark conditions, interfaced to a personal computer. The illuminated current-voltage characteristics of $\mathrm{Au} / \mathrm{CuTTP} / \mathrm{p}-\mathrm{Si} / \mathrm{Al}$ heterojunct-ion were also measured by using Keithley electrometers model 617. The incident white light provided by halogen lamp of intensity $5 \mathrm{~mW} / \mathrm{cm}^{2}$, falls normally through the gold window on the organic film. The intensity of the incident light is recorded by a digital light meter (Lutro-Model LX-107).

\subsection{Dark current-voltage characteristics}

\section{Results And Discussions}

Fig.1 shows a semi logarithmic plot of the forward and reverse currents versus the applied voltage of $\mathrm{Au} / \mathrm{CuTPP} / \mathrm{p}-\mathrm{Si} / \mathrm{Al} \mathrm{p}-\mathrm{Si}$ heterojunction in the temperature range $293-353 \mathrm{~K}$. The values of the current increases as the temperature increase. The heterojunction exhibits rectification behavior showing a diode-like characteristic. The specific parameters of the heterojunction such as the diode quality factor $(\mathrm{m})$, the rectification ratio $(R R)$, the series resistance $\left(R_{s}\right)$, the shunt resistance $\left(R_{\text {sh }}\right)$, the barrier height at the interface of the junction $\left(\Phi_{\mathrm{b}}\right)$ can de estimated from I-V characteristics curves. The maximum rectification ratio is observed at $\pm 0.25 \mathrm{~V}$ at room temperature condition as shown in Fig.2.

The junction resistance, $R_{j}$ of $\mathrm{Au} / \mathrm{CuTPP} / \mathrm{p}-\mathrm{Si} / \mathrm{Al} \mathrm{p}-\mathrm{Si}$ heterojunction is determined from $\mathrm{I}-\mathrm{V}$ characteristic curves according to following formula [12]:

$$
R_{j}=\frac{\partial V}{\partial I}
$$

By plotting the junction resistance, $R_{j}$, as an ordinate versus bias potential, the series, $R_{s}$, and the shunt, $R_{s h}$, resistances are estimated. Fig. 3 shows that the junction resistance arrives to a nearly constant value under forward bias which is $R_{S}$. The same behavior occurs also under reverse bias potential leading to determination of $R_{s h}$. The estimated values of $R_{s}$ and $R_{s h}$ are found to be 42.864 and $96.341 \mathrm{k} \Omega$, respectively.

The dark current-voltage characteristics are extremely useful for identifying the transport mechanisms operating conduction. Fig.4 shows the current-voltage (I-V) characteristics observed for the heterojunction under the forward bias at different temperatures. For each curve; there are two distinct voltage regions indicated that there are two different predominant conduction mechanisms. In the first low voltage region $0<\mathrm{V}<0.2$ Volt; as shown in Fig.4 the relation between $\mathrm{lnI}$ versus $\mathrm{V}$ is linear and the current of the Au/CuTPP/p-Si/Al device obeys the thermoionic emission over the organic/inorganic barrier in the heterojunction. According to this conduction mechanism, the heterojunction current is given by [13-14].

$$
I=I_{01}\left(\exp \left(\frac{q V}{m_{1} k_{B} T}\right)-1\right)
$$

Where $q$ the electric charge, $k_{B}$ the Boltzmann's constant, $T$ the absolute temperature and $m_{l}$ is the ideality factor which determined from the slope of the linear region of the forward bias $\ln (\mathrm{I})$-V (Fig.4).

Fig.5 shows the ideality factor, $\mathrm{m}_{1}$, as a function of temperature, the figure indicated that the ideality factor decrease with increasing temperature in the range of temperature $293-353 \mathrm{~K}$. The value of $\mathrm{m}_{1}$ is higher than the unity which may be attributed to either recombination of free carriers in depletion region or the increase of diffusion current [15]. To confirm that the thermoionic emission, at the first low voltage region, is the operating mechanism more analysis must be carried out. According to the thermoionic emission the saturation current $\mathrm{I}_{01}$ is given by[13-14]: 
$\ln \left[\frac{I_{01}}{T^{2}}\right]=\ln C+\left[\frac{-q \phi_{b 0}}{k_{B}}\right] \frac{1}{T}$

Where $\phi_{b 0}$ is the effective barrier height at the CuTPP/p-Si interface at zero bias, C is a constant. The plot of $1 \mathrm{n}\left(\mathrm{I}_{01} / \mathrm{T}^{2}\right)$ versus 1000/T supports the thermoionic emission mechanism in the applied voltage range $0<\mathrm{V}<0.2$ Volt, as shown in Fig.6. The effective barrier height, $\phi_{b 0}$, is determined as $\sim 0.37 \mathrm{eV}$ is calculated from the slope according to Eq.(3). It is well known the ideality factor in organic/inorganic heterojunction depends on electrode material [16], regardless that for barrier height.

Under high voltage region $(\mathrm{V}>0.35 \mathrm{~V})$, the transport through organic materials is governed by spacecharge limited currents (SCLC) mechanism is dominated in this voltage range, the current density will obey the following equation [17]

$J_{S C L C}=\frac{9}{8} \varepsilon_{0} \theta \mu \frac{V^{2}}{d^{3}}$

where $\varepsilon_{0}$ is permittivity of free space of CuTPP, $\mu$ is the carrier mobility, $\mathrm{d}$ is the film thickness and $\theta$ is the trapping factor. Fig. 7 shows the semi logarithms of forward current versus applied voltage at different temperature. This relation shows power law dependence with order $\approx 2$ indicating that the SCLC with a single trap level is the dominant in this voltage range.

The trapping factor $\theta$ is defined by the ratio of free charge to trapped charge and given by:

$\theta=\frac{N_{v}}{N_{t}} \exp \left(\frac{-E_{t}}{K_{B} T}\right)$

Where $N_{t}$ is the total trap concentration at energy level $E_{t}$ above the valence band edge and $N_{v}$ is the effective density of states at the valence band edge. Fig. 8 shows the temperature dependence of $\ln \left(\mathrm{I}_{\mathrm{f}}\right)$ in the space charge region. The trap level $E_{t}$ is determined from the slope of the curves and has the value of $0.3 \mathrm{eV}$.

The dark reverse $I_{R}-V$ characteristics at different temperatures are shown in Fig.9. The reverse current shows a small dependence on voltage, although it increases with temperature. This indicates that the reverse current should be limited by another transport mechanism. The junction leakage was primarily dominated by the generation and recombination of carriers in the Si substrate [18, 19].The resulting reverse current from generation recombination of carriers is thermally activated and is governed by [20]:

$I_{R}=I_{O R} \exp \left(\frac{\Delta E}{k_{B} T}\right)$

where $\Delta E$ is the carriers activation energy which determined from the slope of these straight line. The value of $\Delta E$ is calculated and found to be 0.43 , This value is nearly equal one half of the energy band of Si substrate $\left(\mathrm{E}_{\mathrm{g}}(\mathrm{Si})=1.1 \mathrm{eV}\right)[19]$, which confirms that the temperature and voltage dependence of the dark reverse current is governed by generation and recombination of charge carriers in $\mathrm{Si}$ substrate rather than at organic-inorganic interface or organic material.

\subsection{Capacitance-voltage characteristics}

The dark capacitance-voltage characteristics of $\mathrm{Au} / \mathrm{CuTPPCl} / \mathrm{p}-\mathrm{Si} / \mathrm{Al}$ heterojunction were measured at room temperature $(293 \mathrm{~K})$. High frequency $(1 \mathrm{MHz})$ is used to investigate the device capacitance, because the data obtained from the $\mathrm{C}-\mathrm{V}$ measurement in the low frequencies range represents the sum of the space charge capacitance and the interface capacitance. As the frequency increases, the interface capacitance contribution to the device capacitance decreases [21].

Fig. 10 shows the relation between measured capacitance, $\mathrm{C}$ versus the applied reverse voltage. The relation between the junction capacitance and the reverse applied potential of an abrupt junction can be given by [22]:

$$
C^{2}=\frac{q \varepsilon_{S} N_{a} A^{2}}{2\left(V_{d o}-V_{a p p l}\right)}
$$

where $\varepsilon_{S}$ is the dielectric constant of $\mathrm{p}-\mathrm{Si}$ and $V_{d o}$ is the diffusion potential at zero bias. The inset of Fig.10 shows the plotting of $\left(1 / \mathrm{C}^{2}\right)$ versus the reverse applied voltage. It is observed that $\left(1 / \mathrm{C}^{2}\right)$ increase linearly by increasing the reverse applied voltage. The linearity of this relation indicates that the junction is considered as 
an abrupt heterojunction. The diffusion potential determined from the extrapolation of the linear parts of $\left(1 / \mathrm{C}^{2}-\right.$ $\mathrm{V})$ plot to the $\mathrm{V}$ axis value which is found to be $0.43 \mathrm{eV}$. The doping concentration value is obtained from the slope and calculated as $5.9 \times 10^{21} \mathrm{~m}^{-3}$.

The barrier height can be determined from the relation [23]:

$$
\phi(C-V)=V_{d o}+V_{p}
$$

where $V_{p}$ is the potential difference between the top of the valence band in the neutral region of $\mathrm{p}-\mathrm{Si}$ and the Fermi level. The value of $V_{p}$ has been calculated as $0.228 \mathrm{eV}$ [22]. Therefore, the barrier height of value 0.65 $\mathrm{eV}$. The discrepancy between the barrier height obtained from the $(\mathrm{I}-\mathrm{V})$ and that obtained from $(\mathrm{C}-\mathrm{V})$ may be due to existence of excess capacitance at the structure or presence of barrier height inhomogeneity [23]. The difference between calculated values of barrier heights suggested that the barriers are non-uniform.

\subsection{Photovoltaic characteristics}

$\mathrm{I}-\mathrm{V}$ characteristic of $\mathrm{Au} / \mathrm{CuTPP} / \mathrm{p}-\mathrm{Si} / \mathrm{Al}$ heterojunction heterojunction measured at room temperature under illumination is shown in Fig.11. Under illumination, the light generates carrier-contribution photocurrent due to the production of electron-hole pairs as a result of the light absorption. As it can be seen from Fig.11; the values of open circuit voltage $\left(\mathrm{V}_{\mathrm{oc}}\right)$, short circuit current $\left(\mathrm{I}_{\mathrm{sc}}\right)$, voltage at maximum power $\left(\mathrm{V}_{\mathrm{M}}\right)$ and current at maximum power point $\left(\mathrm{I}_{\mathrm{M}}\right)$ for the device are: $0.289 \mathrm{~V}, 0.03 \mathrm{~mA}, 0.16 \mathrm{~V}$ and $\mathrm{I}_{\mathrm{M}}=0.022 \mathrm{~mA}$; respectively. The filling factor $(\mathrm{FF})$ is given by $\mathrm{FF}=\mathrm{V}_{\mathrm{M}} \mathrm{I}_{\mathrm{M}} / \mathrm{V}_{\mathrm{oc}} \mathrm{I}_{\mathrm{SC}}$. The calculated value of $\mathrm{FF}$ is 0.39 . The experimental power conversion efficiency of a solar cell is given by: $\eta=F F V_{O C} I_{S C} / A P_{I n}$ where $P_{I n}$ is illumination intensity $\approx 5 \mathrm{~mW} / \mathrm{cm}^{2}$ and $\mathrm{A}$ is the effective area $=2 \mathrm{~mm}^{2}$. The calculated value of cell efficiency is $3.4 \%$. The efficiency had been calculated without correcting for reflection or electrode absorption losses. The calculated parameters are compared with those other some solar cells based porphyrin systems are listed in Table1.

\section{Conclusion}

Organic-inorganic heterojunction $\mathrm{Au} / \mathrm{CuTPP} / \mathrm{p}-\mathrm{Si}-\mathrm{Al}$ was prepared using thermal evaporation technique. The $\mathrm{I}-\mathrm{V}$ characteristics demonstrated a rectification behavior of $\mathrm{p}-\mathrm{n}$ heterojunction. The basic diode parameters such as the ideality factor, series resistance and the barrier height were extracted from the $\mathrm{I}-\mathrm{V}$ measurement of Au/CuTPP/p-Si/Al. There are two basic conduction mechanisms operating in $\mathrm{Au} / \mathrm{CuTPP} / \mathrm{p}-$ $\mathrm{Si} / \mathrm{Al}$ heterojunction solar cell and they are depending upon applied potential. Thermionic emission conduction mechanism is operating in the lower voltage range $(0<\mathrm{V}<0.2 \mathrm{~V})$; followed by SCLC with a single trap level in the potential range greater than $0.35 \mathrm{~V}$. The values of open circuit voltage, short circuit current and voltage at maximum power, current at maximum power, fill factor and power conversion efficiency of the device are: $0.28 \mathrm{~V}, 0.03 \mathrm{~mA}, 0.16 \mathrm{~V}, 0.022 \mathrm{~mA}, 0.39$ and $3.4 \%$, respectively.

\section{References}

[1]. J. J. M. Halls, C. A.Walsh, N. C. Greenham, E. A. Marseglia, R. H. Friend, S. C. Moratti, , and A. B.Holmes, Nature 376(1995) 498.

[2]. G. Yu, J. Gao, J. C. Hummelen, F. Wudl, and A. J. Heeger, Science 270(1995) 1789.

[3]. B. Kraabel, J. C. Hummelen, D. Vacar, D. Moses, N. S. Sariciftci, A. J. Heeger, and F. Wudl, J. Chem. Phys. 104(1996) 4267.

[4]. http://en.wikipedia.org/wiki/Porphyrin.

[5]. J.Milliron, Ilan. Gur, A. Paul, MRS Bulletin 30(2005) 44.

[6]. H.Gerischer,M. Michel-Beyerle,E. Rebentrost, H. Tributsch, "Sensitization of Charge-Injection into Semiconductors with Large Band Gap".

[7]. A. Kay and M.Grätzel, J. Phys. Chem, 97(1993)6272.

[8]. A. Kay, R.Humphry and M.Grätzel, M. J. Phys.Chem, 98(1994) 952.

[9]. M. Victoria, G. Torre and T. Torres,Chem. Commun., 46(2010)7090-7108.

[10]. G.Michael , B.Alexander and C.Wamser, Journal of Porphyrins and Phthalocyanines ,14( 2010)759.

[11]. X.Wang and H.Tamiaki, Energy Environ. Sci,3(2009) 94.

[12]. S.Riad, Thin Solid Films, 370 (2000) 253.

[13]. M.Shimura and A.Toyoda, Jpn.J.Appl.Phys, 23(1984)1462.

[14]. D.V.Morgan, Y.Aliyu and R.W.Bunce, Phys.Status Solidi, A133(1992)77.

[15]. T.S.Shafai and T.D.Anthopoulos, Thin Solid Films, 398(2001)361.

[16]. S.R.Forrest, M.L.Kalplan and P.M.Schmidty, J.Appl.Phys, 56(1984)543.

[17]. M.A. Lampert, Rep. Prog. Phys. 27 (1964) 329

[18]. S.R. Forrest, J. Phys.: Condens. Mater. 15 (2003) S2599.

[19]. M.M. El-Nahass, H.S. Metwally, H.E.A. El-Sayed and A.M. Hassanien, Synthetic Metals ,161 (2011) 2253.

[20]. M.M. Ahmed, Kh.S. Karimov, S.A. Moiz, IEEE Trans. Electron, 51 (2004) 121.

[21]. B.Boyarbay,H.Cetin,A.Uygun and E.Ayyildiz, Thin Solid Films 518(2010)2216.

[22]. N. Kavasoglu, C. Tozlu, O. Pakma, A.S. Kavasoglu, S. Ozden, B. Metin, O. Birgi and S. Oktik, Synthetic Met. 159 (2009) 1880.

[23]. F.Yakuphanoglu,Synth.Met.158(2008)108.

[24]. K. Takahashi, S. Nakatani, T. Yamaguchi, T. Komura, S. Ito and K. Murata, Sol. Energy Mater. Sol. Cell 45 (1997) 127.

[25]. M.M. El-Nahass, H.M. Zeyada, M.S. Aziz, M.M. Makhlouf, Thin Solid Films 492(2005) 290. 
Table.1 Parameters of some organic solar cells based on porphyrin system.

\begin{tabular}{|c|c|c|c|c|}
\hline $\begin{array}{c}\text { Solar cell } \\
\text { construction }\end{array}$ & $\mathrm{V}_{\text {oc }}(\mathrm{V})$ & $\begin{array}{c}\text { Fill } \\
\text { Factor }\end{array}$ & Efficiency\% & Ref. \\
\hline $\mathrm{Au} / \mathrm{CuTPP} / \mathrm{p}-\mathrm{Si} / \mathrm{Al}$ & 0.289 & 0.39 & 3.4 & $\begin{array}{c}\text { Present } \\
\text { work }\end{array}$ \\
\hline $\mathrm{Al} / \mathrm{TPP} / \mathrm{Au}$ & 0.74 & 0.18 & 0.06 & {$[24]$} \\
\hline $\mathrm{Au} / \mathrm{TPP} / \mathrm{p}-\mathrm{Si} / \mathrm{Al}$ & 0.25 & 0.37 & 2.45 & {$[25]$} \\
\hline $\begin{array}{c}\mathrm{Au} / \mathrm{FeTPPl} / \mathrm{p}- \\
\mathrm{Si} / \mathrm{Al}\end{array}$ & 0.47 & 0.32 & 5 & {$[19]$} \\
\hline
\end{tabular}

Figure captions:

Fig .1 I-V characteristic in the dark at different temperature in forward and reverse bias.

Fig.2 Relation between the rectifation ratio, RR, and the bias potential for $\mathrm{Au} / \mathrm{CuTPP} / \mathrm{p}-\mathrm{Si} / \mathrm{Al}$ heterojunction diode.

Fig.3 Relation between the junction resistance, $R_{j}$, and the bias potential for $\mathrm{Au} / \mathrm{CuTPP} / \mathrm{p}-\mathrm{Si} / \mathrm{Al}$ heterojunction.

Fig.4 Dark I-V characteristics of CuTPP/p-Si/Al at different temperature in forward bias.

Fig.5 Temperature dependence of ideality factor, $\mathrm{m}_{1,}$, for $\mathrm{Au} / \mathrm{CuTPP} / \mathrm{p}-\mathrm{Si} / \mathrm{Al}$ hetrojunction.

Fig.6 The plotting of $1 \mathrm{n}$ saturated current divided by $\mathrm{T}^{2}$ vs. 1000/T at the first region.

Fig.7 Shows the semi logarithms of forward current verse semi logarithms applied voltage at different temperature.

Fig.8 Temperature dependence of $\ln \left(\mathrm{I}_{\mathrm{f}}\right)$ at 1 and $1.5 \mathrm{~V}$

Fig.9 Plot of of $\ln \left(\mathrm{I}_{\mathrm{R}} / \mathrm{T}^{2}\right)$ vs. 1000/T.

Fig.10 Plot of $\mathrm{C}^{-2}-\mathrm{V}_{1}$ characteristics of the Au/CuTPP/p-Si hetrojunction.

Fig.11 Current -voltage characteristics curve for Au/CuTPP/p-Si/Al p-Si heterojunction under illumination conditions at room temperature.

Fig .1

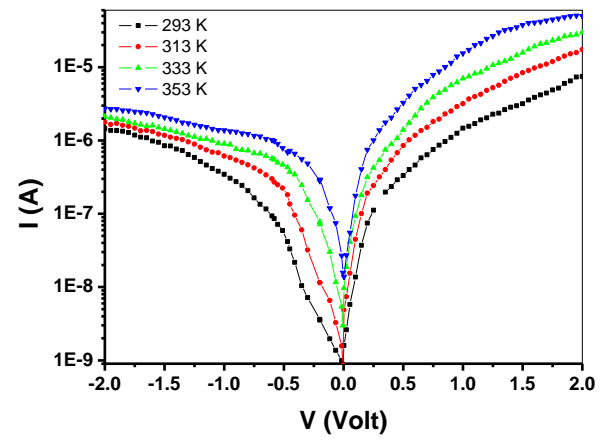

Fig .2

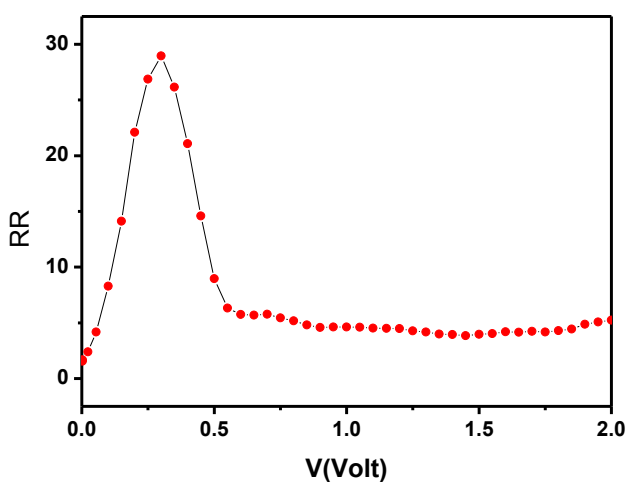


Fig.3

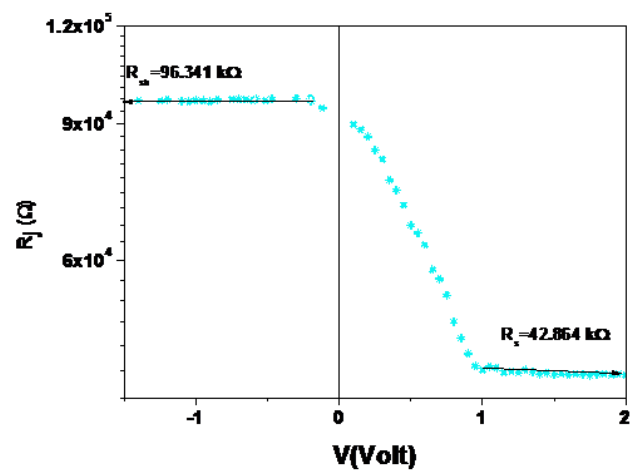

Fig .4

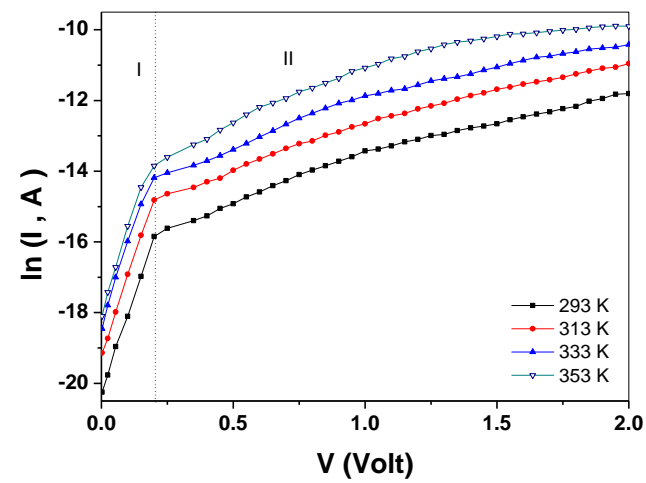

Fig .5

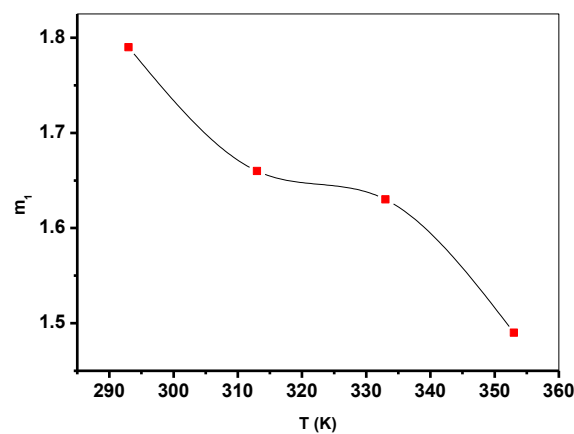

Fig .6

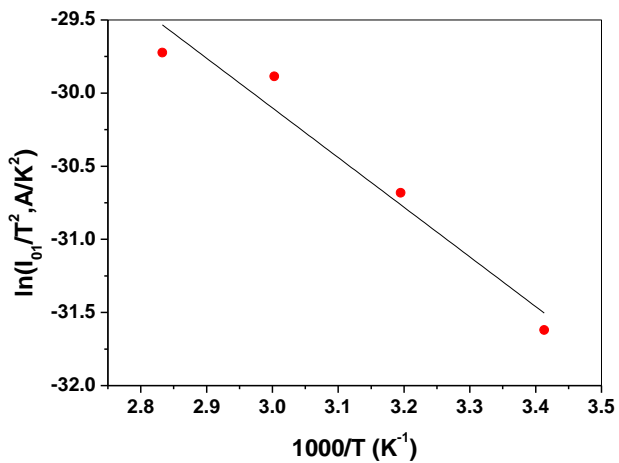


Fig .7

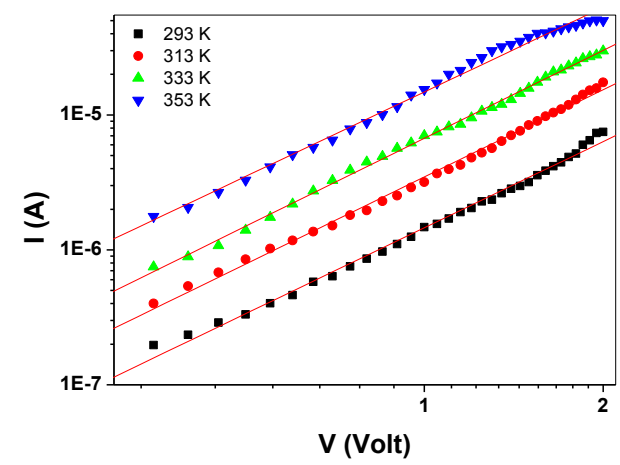

Fig .8

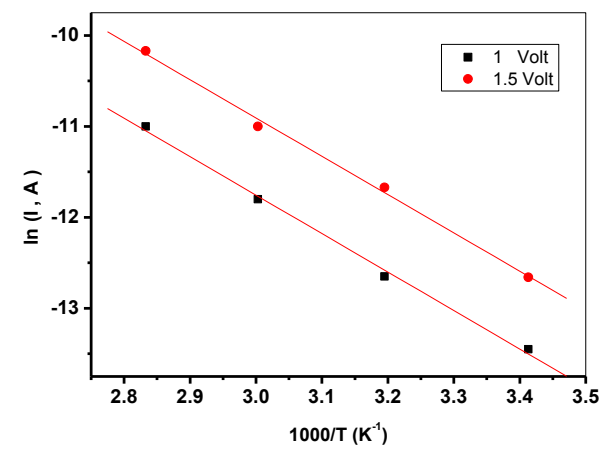

Fig .9

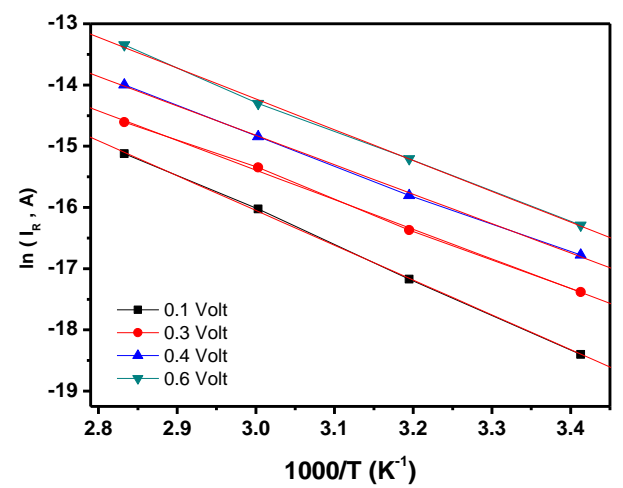

Fig.10

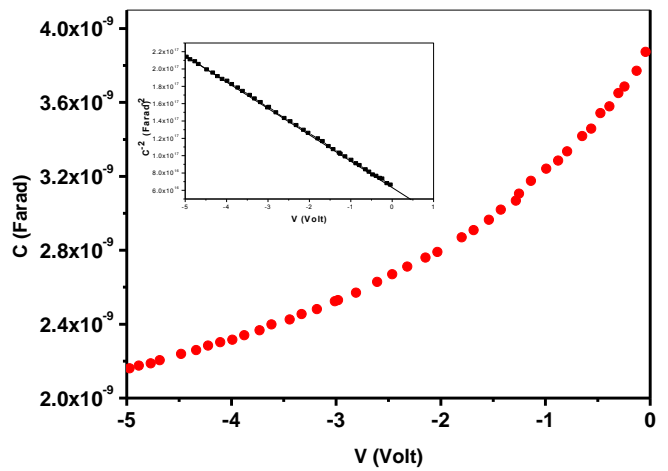


Fig .11

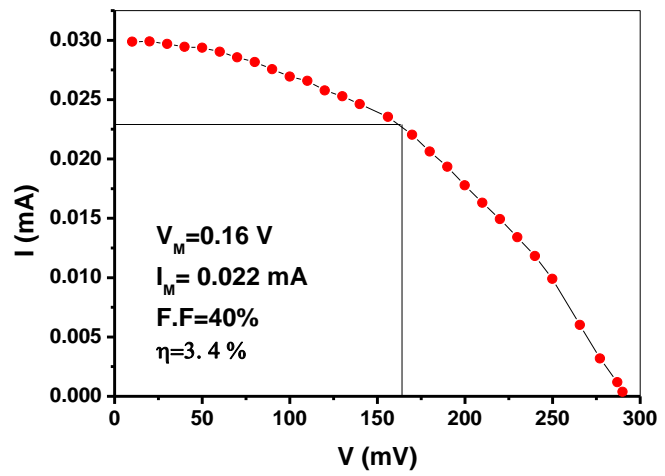

